\title{
$\mathrm{J}$

\section{Gas Phase Acidity Measurement of Local Acidic Groups in Multifunctional Species: Controlling the Binding Sites in Hydroxycinnamic Acids}

Andres Guerrero, ${ }^{* \dagger}{ }^{\dagger}$ Tomas Baer, ${ }^{\ddagger}$ Antonio Chana, Javier González, and Juan Z. Dávalos*

Instituto de Química Física "Rocasolano”, CSIC, C Serrano 119, Madrid, E-28006, Spain

Supporting Information

\begin{abstract}
The applicability of the extended kinetic method (EKM) to determine the gas phase acidities (GA) of different deprotonable groups within the same molecule was tested by measuring the acidities of cinnamic, coumaric, and caffeic acids. These molecules differ not only in the number of acidic groups but in their nature, intramolecular distances, and calculated GAs. In order to determine independently the GA of groups within the same molecule using the EKM, it is necessary to selectively prepare pure forms of the hydrogen-bound heterodimer. In

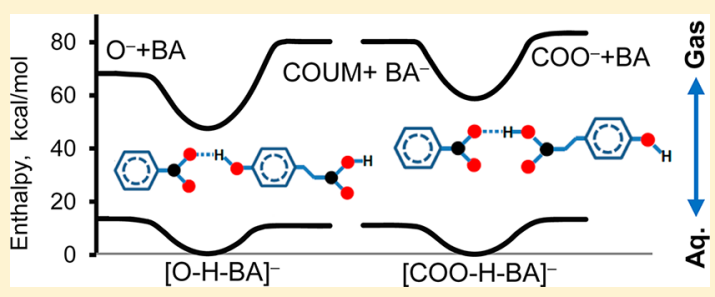
this work, the selectivity was achieved by the use of solvents of different vapor pressure (water and acetonitrile), as well as by variation of the drying temperature in the ESI source, which affected the production of heterodimers with different solvation energies and gas-phase dissociation energies. A particularly surprising finding is that the calculated solvation enthalpies of water and the aprotic acetonitrile are essentially identical, and that the different gas-phase products generated are apparently the result of their different vapor pressures, which affects the drying mechanism. This approach for the selective preparation of heterodimers, which is based on the energetics, appears to be quite general and should prove useful for other studies that require the selective production of heterodimers in ESI sources. The experimental results were supported by density functional theory (DFT) calculations of both gas-phase and solvated species. The experimental thermochemical parameters (deprotonation $\Delta G$, $\Delta H$, and $\Delta S$ ) are in good agreement with the calculated values for the monofunctional cinnamic acid, as well as the multifunctional coumaric and caffeic acids. The measured GA for cinnamic acid is $334.5 \pm 2.0 \mathrm{kcal} / \mathrm{mol}$. The measured acidities for the $\mathrm{COOH}$ and $\mathrm{OH}$ groups of coumaric and caffeic acids are $332.7 \pm 2.0,318.7 \pm 2.1,332.2 \pm 2.0$, and $317.3 \pm 2.2 \mathrm{kcal} / \mathrm{mol}$, respectively.
\end{abstract}

\section{INTRODUCTION}

The developments of electrospray ionization (ESI) and matrix assisted laser desorption ionization (MALDI), which generate ions directly from condensed phase samples, have revolutionized mass spectrometry by overcoming one of its main limitations: the dependence on the volatility of the samples. As a result, important thermally labile biological species such as amino acids and peptides can now be routinely investigated by mass spectrometry. On the other hand, the usual methodologies established for the study of thermochemical properties by mass spectrometry use ion-molecule reactions for which the presence of neutral species is necessary. Among these are the equilibrium method, ${ }^{1-10}$ the kinetic bracketing technique, ${ }^{11-18}$ and the Bouchoux thermokinetic approach, ${ }^{19-21}$ all of which require volatile neutral reaction partners.

The kinetic method (KM) developed by Cooks et al. in $1977^{22,23}$ greatly expanded the range of systems that can be investigated by eliminating the need for a neutral reaction partner. Moreover, the KM is conceptually simple, easy to use, reproducible, not affected by the presence of contaminants, and can be applied to determine various thermochemical properties such as gas-phase basicities (GBs), gas-phase acidities (GAs), or metal salt affinities. Finally, it does not depend on knowing the pressure inside of the instrument. Briefly, the KM is based on the rates of competitive dissociation of mass-selected cluster ions formed between a sample and a reference of known thermochemical properties. For instance, if the GA of the AH molecule is of interest, one can generate a hydrogen bridged cluster anion between it and a reference acid, $\mathrm{R}_{\mathrm{ref}} \mathrm{H}$, whose $\mathrm{GA}$ is known (see Scheme 1).

Scheme 1

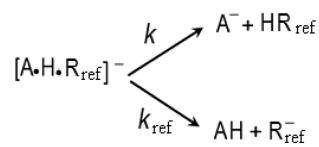

Under appropriate conditions, these rates can yield quantitative thermochemical information relative to the reference. During the last 30 years, the method has been revised and improved by the contribution of many groups including Fenselau, ${ }^{24,25}$ Wesdemiotis, ${ }^{26-28}$ Armentrout, ${ }^{29-31}$ and Ervin. ${ }^{32}$ As a result, the $\mathrm{KM}$ has become one of the most frequently used experimental approaches for measuring

Received: January 17, 2013

Published: May 15, 2013 
thermochemical parameters by mass spectrometry, ${ }^{33-36}$ and its use has been expanded to include the study of enantiomeric analysis of optically active compounds. ${ }^{37,38}$

As the use of electrospray and the kinetic method has expanded to include larger molecules with multiple functional groups, ${ }^{39,40}$ important questions have been raised about the location of protonation and the binding of other acids. Is the binding site determined by kinetics or by thermochemistry? If binding takes place at the thermochemically most favorable site, are the relevant energetics established by the solvent phase or the gas phase, ${ }^{41}$ or indeed somewhere in between? As has been known for many years, ${ }^{42}$ and recently emphasized by Joyce and Richards, ${ }^{43}$ solvation energies can invert the stabilities relative to the gas phase. Furthermore, it is commonly assumed that replacing water with an aprotic solvent such as acetonitrile results in an anion that most "likely adopts its gas-phase structure". ${ }^{44}$ Indeed, Kass et al. ${ }^{45-47}$ and Steill and Oomens ${ }^{44}$ have successfully taken advantage of solvent effects to generate different gas-phase deprotonated and protonated ions of bifunctional molecules such as hydroxybenzoic and aminobenzoic acids. In the case of hydroxybenzoic acid, the site of deprotonation was monitored by photoelectron spectroscopy. ${ }^{46}$ However, the results appeared to depend on the type of ESI source used in that one favored the production of gas-phase carboxylate ions while the other source showed no preference. In response to this study, Steill and Oomens ${ }^{44}$ used an ESI source coupled to an IR study, and found that acetonitrile solvent favored the gas-phase production of the phenoxy ions, which is more consistent with the idea that acetonitrile solvents favor the lower energy gas-phase isomer. From these results, it is clear that the mechanism for the selectivity is not understood. One problem with both of these studies is that they look only at the gas-phase structures and try to infer what is happening in solution. In order to learn the effect of solvent on the solution phase species directly, Schroeder et al. ${ }^{48}$ studied the solution phase NMR of $p$-hydroxybenzoic acid and its deprotonation site, and showed that deprotonation at the $\mathrm{COOH}$ site is somewhat preferred with both water and acetonitrile solvents.

In this study, we explore the use of the kinetic method to determine the GAs of different sites in multifunctional acids, and in the process lend further insight into the desolvation mechanism in ESI. If a molecule, HABH, has two acidic sites, the reference acid, $\mathrm{R}_{\mathrm{ref}} \mathrm{H}$, can be attached on either site, yielding a mixture of isomeric heterodimers. Upon collision with a gas, the two heterodimers dissociate (Scheme 2) to three different product anions, two of which, $\mathrm{HAB}^{-}$and $\mathrm{ABH}^{-}$, have different structures but equal mass.

\section{Scheme 2}

$$
\left[\mathrm{R}_{\text {ref } \cdot H \cdot A B H]^{-}} \sum_{\mathrm{HABH}+\mathrm{R}_{\text {ref }}^{-}}^{\mathrm{ABH}^{-}+\mathrm{HR}_{\mathrm{ref}}}\right.
$$

For this study, we have chosen three related carboxylic acids: trans-cinnamic acid, $p$-coumaric acid, and caffeic acid, the latter two having also hydroxyl groups (Figure 1). Hydroxycinnamic acids are natural compounds found in several biological sources mostly in the plant kingdom either as esters of organic acids or glycosides, bound to proteins or as free acids.

A number of years ago, Hoke and co-workers ${ }^{49}$ reported on the application of the KM to such bifunctional systems. In that<smiles>O=C(O)/C=C/c1ccccc1</smiles><smiles>O=C(O)/C=C/c1ccc(O)cc1</smiles>

trans-Cinnamic acid

p-Coumaric acid<smiles>O=C(O)/C=C/c1ccc(O)c(O)c1</smiles>

Caffeic acid

study of methyl phenol, they obtained a two-slope plot which was assigned to the formation of two different isomeric clusters, from which they obtained the proton affinities of the $o$ hydroxybenzyl and its isomer, $o$-methylphenoxyl radicals. However, this study did not look critically at the implications of their two-slope plot. The authors assumed that each trend line corresponds to the dissociation of one specific isomeric heterodimer, not a mixture of the two possible clusters. Since then, a few other groups have investigated bifunctional ions using the kinetic method, with mixed results. Bouchoux et al. ${ }^{50}$ investigated a number of open chain bifunctional molecules and obtained inconsistent proton affinities that could not be correlated with calculated values. They concluded that the use of the kinetic method for "bidentate molecules is not optimistic". More recently, Fournier et al. ${ }^{51}$ investigated a series of amino acids, and found two slopes in their extended KM plots for some of the samples. They were attributed to the presence of zwitterion structures which dissociated differently at higher collision energies, an effect that is very different from the two-slope features in the earlier Hoke et al. study.

In the present study of the coumaric and caffeic acids, we have found that the problem presented by multifunctional groups is somewhat more complex and conclude that only by a careful control of the experimental conditions is it possible to generate proton bound heterodimers exclusively formed by one isomeric form, and thus to extract reliable thermodynamic properties of the individual functional groups.

\section{EXPERIMENTAL SECTION}

Materials and Instrumentation. Cinnamic, coumaric, and caffeic acid as well as the reference acids (shown in Table S1 of the Supporting Information) were obtained from Sigma-Aldrich and Alfa Aesar and used without further purification. The reference acids were chosen on the basis of their similar $\mathrm{GA}^{52}$ to that calculated for the hydroxycinnamic acids and, when possible, based also on their structural similarity.

The experiments were performed on a triple quadrupole mass spectrometer Agilent/Varian 320 equipped with an electrospray ionization (ESI) source. Approximately $5 \times 10^{-5} \mathrm{M}$ hydroxycinnamic acid and the desired reference acid were mixed in a 1:1 mass ratio. The solutions were directly infused into the ESI ionization source in the negative mode at flow rates of $10 \mu \mathrm{L} / \mathrm{min}$. The temperature of the drying gas and the solvents were chosen in order to promote the formation of specific proton bound heterodimeric anions.

The cluster anions were isolated in the first quadrupole, underwent collision induced dissociation (CID) in the second quadrupole, and the resulting fragments analyzed in the third quadrupole. CID experiments were performed using argon as a collision gas ( 0.2 mbar) at various ion kinetic energies in the collision cell. The center of mass energy $\left(E_{\mathrm{cm}}\right)$ was calculated as $E_{\mathrm{cm}}=E_{\mathrm{lab}}[m /(M+m)]$, where $E_{\text {lab }}$ is the ion kinetic energy in the laboratory frame, $m$ is the mass of the collision gas, and $M$ is the mass of the heterodimeric anion. The final product ion abundances are based on the average of 500 measurements obtained over several days.

Extended Kinetic Method. The GA is defined as the Gibbs freeenergy change $\left(\Delta_{\mathrm{a}} G\right)$ of the deprotonation reaction generally at $298.15 \mathrm{~K}$ (eq 1). The deprotonation enthalpy $\left(\Delta_{\mathrm{a}} H\right)$ and 
deprotonation entropy $\left(\Delta_{a} S\right)$ are the enthalpy and entropy changes of the same reaction.

$$
\mathrm{AH} \rightarrow \mathrm{A}^{-}+\mathrm{H}^{+}
$$

The determination of the GA by the KM starts with the formation of proton-bound heterodimer anions between the sample and a series of reference acids of known GA. The heterodimer is fragmented by collision induced dissociation (CID) to yield the corresponding monomeric anions of the sample $\left(\mathrm{A}^{-}\right)$and the reference $\left(\mathrm{R}_{\mathrm{ref}}{ }^{-}\right)$. If secondary fragmentation is negligible, the abundance ratio of these fragment ions is equal to the ratio of the two dissociation rate constants, $k$ and $k_{\text {ref }}$ (Scheme 1).

With the assumption that there are no reverse activation barriers, the GAs of the sample and the reference are related by the second equality in eq 2, where $R$ is the universal gas constant and $T_{\text {eff }}$ is the effective temperature of the activated system. ${ }^{32}$ In the extended kinetic method (EKM), the free energy $(\Delta G)$ is replaced by its definition in terms of the enthalpy and entropy of the reactions (third equality in eq 2 ), and it is recognized that both $\Delta H$ and $\Delta S$ can be determined by varying the $T_{\text {eff }}$ In eq $2, \Delta(\Delta S)=\Delta_{\mathrm{a}} S-\Delta_{\mathrm{a}} S_{\text {ref }}$

$$
\begin{aligned}
\ln \left(\frac{k}{k_{\text {ref }}}\right) & =\ln \left(\frac{\left[\mathrm{A}^{-}\right]}{\left[\mathrm{R}_{\text {ref }}^{-}\right]}\right) \\
& =\frac{\Delta_{\mathrm{a}} G_{\text {ref }}-\Delta_{\mathrm{a}} G}{R T_{\text {eff }}} \\
& =\frac{\Delta_{\mathrm{a}} H_{\text {ref }}-\Delta_{\mathrm{a}} H}{R T_{\text {eff }}}+\frac{\Delta(\Delta S)}{R}
\end{aligned}
$$

In an effort to avoid the correlation in errors between the enthalpy and entropy differences, Armentrout ${ }^{29}$ suggested converting eq 2 into eq 3 , so that the plot can be constructed with the reference enthalpy relative to the average enthalpies of the reference acids.

$$
\begin{aligned}
\ln \left(\frac{\left[\mathrm{A}^{-}\right]}{\left[\mathrm{R}_{\mathrm{ref}}^{-}\right]}\right)= & \frac{\Delta_{\mathrm{a}} H_{\mathrm{ref}}-\Delta_{\mathrm{a}} H_{\mathrm{avg}}}{R T_{\text {eff }}}-\left(\frac{\Delta_{\mathrm{a}} H-\Delta_{\mathrm{a}} H_{\mathrm{avg}}}{R T_{\text {eff }}}\right. \\
& \left.-\frac{\Delta(\Delta S)}{R}\right)
\end{aligned}
$$

We now have three unknowns in eq $3, \Delta_{\mathrm{a}} H, R T_{\text {eff }}$ and $\Delta(\Delta S)$. These quantities are then obtained from two sets of thermo-kinetic plots based on eq 3 . The first set is the linear plot of $\ln \left(\left[\mathrm{A}^{-}\right] /\left[\mathrm{R}^{-}\right]\right)$against $\left(\Delta_{\mathrm{a}} H_{\text {ref }}-\Delta_{\mathrm{a}} H_{\text {avg }}\right)$ using data collected at a series of different collision energies. The resulting plots give a series of straight lines with a slope of $1 / R T_{\text {eff }}$ and a $y$-intercept of $-\left[\left(\Delta_{\mathrm{a}} H-\Delta_{\mathrm{a}} H_{\text {avg }}\right) / R T_{\text {eff }}-\Delta(\Delta S) / R\right]$. In the second thermo-kinetic plot, the values of the intercepts obtained in the first graph are plotted against their corresponding slopes. The new linear regression line will yield $\Delta_{\mathrm{a}} H-\Delta_{\mathrm{a}} H_{\text {avg }}$ from the slope and $\Delta(\Delta S) / R$ from the intercept. $\Delta_{\mathrm{a}} H$ can then be obtained from that slope because $\Delta_{\mathrm{a}} H_{\text {avg }}$ is known. If the references have similar deprotonation entropies, the term $\Delta_{\mathrm{a}} S_{\text {ref }}$ can be substituted for the average deprotonation entropy of the references, $\Delta_{a} S_{\text {avg }}$, so that $\Delta_{a} S$ is obtained. Finally, the GA of the sample can be derived by eq 4 , where $T=298.15 \mathrm{~K}$.

$$
\Delta_{\mathrm{a}} G=\Delta_{\mathrm{a}} H-T\left(\Delta_{\mathrm{a}} S\right)
$$

\section{COMPUTATIONAL DETAILS}

Standard DFT calculations on the various systems under study were performed with the Gaussian 09 suite of programs. ${ }^{53}$ The geometries in the ground state of the neutral and anionic gasphase species, including all the low energy conformers, were calculated by use the Becke 3-parameter and Lee-Yang-Parr (B3LYP) functional ${ }^{54,55}$ with the $6-311++G(d, p)$ basis set without symmetry restrictions. Harmonic vibrational frequencies were also obtained at the same level to verify that the derived structures correspond to local minima of the potential energy surface. GA values of each compound and group were computed as the thermal population weighted average of the thermochemical quantities of the various low energy conformers. Examples of various conformers of cinnamic, coumaric, and caffeic acid are shown in Figure S1 of the Supporting Information. This shows that cinnamic acid has two low lying conformers that differ in their enthalpies by $0.6 \mathrm{kcal} /$ mol. Coumaric acid has four conformers, the three higher lying conformers having energies $0.1,0.6$, and $0.6 \mathrm{kcal} / \mathrm{mol}$ above the most stable form. The thermally weighted deprotonation entropies were obtained from $\Delta_{\mathrm{a}} S=\sum_{1}^{N} x_{i}(S)_{i}-R \sum_{1}^{N} x_{i} \ln x_{i}$, where $x_{i}$ are the mole fractions of the various conformers. The heterodimer structures for coumaric and caffeic acids with benzoic acid are shown in Figure S2 in the Supporting Information.

The ESI source contains solvated species which are important in understanding the experimental observations. The heterodimer stability and dissociation energetics were thus calculated both in the gas phase and in water using the polarizable continuum model ${ }^{56}$ for the two possible isomers of the coumaric-benzoic acid as well as caffeic-benzoic acid anionic clusters. In order to ensure that the solvated structures were true minima, harmonic vibrational frequencies were obtained.

\section{RESULTS}

The Simple Kinetic Method Analysis of a Bifunctional Molecule. The first experiment was to test the applicability of the simple KM for measuring the GA of the bifunctional coumaric acid. The natural logarithms of the branching ratios $\ln \left(\left[\mathrm{A}^{-}\right] /\left[\mathrm{R}_{\mathrm{ref}}^{-}\right]\right)$were plotted against the GA of the reference compounds 2-chlorophenol, phenylacetic acid, benzoic acid, 2toluic acid, 4-hydroxy-benzoic acid, 2-cyano-phenol, 3-trifluorometyl-benzoic acid, 4-nitro-5-methylphenol, and 4-nitrophenol (Figure 2). The GAs for the reference acids were

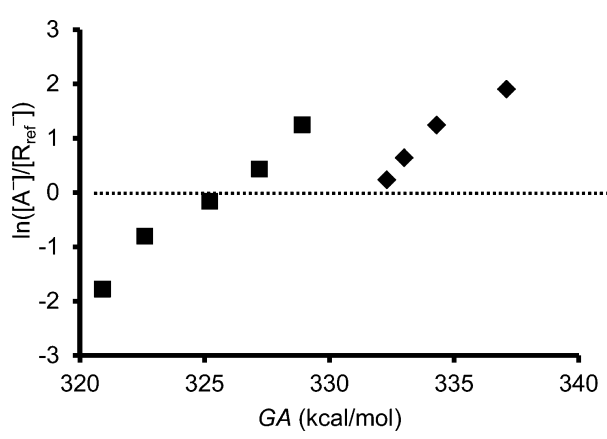

Figure 2. CID $\left(E_{\mathrm{cm}}=1.5 \mathrm{eV}\right)$ natural logarithm of the branching ratios against the GA of the references for coumaric acid. The experiments were performed with 1:1 water/acetonitrile solvent and a drying gas temperature of $180{ }^{\circ} \mathrm{C}$.

taken from the NIST ${ }^{52}$ compilation and have been included in Table S1 (Supporting Information). As in the study of Hoke et al., ${ }^{49}$ a two-slope pattern was obtained, which looks as though the heterodimer produced with the low GA reference acids $(321-329 \mathrm{kcal} / \mathrm{mol})$ has the reference acid attached at the hydroxyl group, whereas the high GA reference acids (333-337 $\mathrm{kcal} / \mathrm{mol}$ ) have the reference acid attached at the carboxylic group. If this were the case, one could extract the two GAs of the coumaric acid from the two intercepts, as indeed was the conclusion of Hoke et al. ${ }^{49}$ 
Table 1. Experimental and DFT-Calculated GAs $\left(\Delta_{\mathrm{a}} G\right)$, Deprotonation Enthalpies $\left(\Delta_{\mathrm{a}} H\right)$, and Entropies $\left(\Delta_{\mathrm{a}} S\right)$ of Hydroxycinnamic Acids

\begin{tabular}{|c|c|c|c|c|c|c|}
\hline \multirow[b]{2}{*}{ compound/group } & \multicolumn{2}{|c|}{$\Delta_{\mathrm{a}} G^{a}(\mathrm{GA}, \mathrm{kcal} / \mathrm{mol})$} & \multicolumn{2}{|c|}{$\Delta_{\mathrm{a}} H(\mathrm{kcal} / \mathrm{mol})$} & \multicolumn{2}{|c|}{$\Delta_{\mathrm{a}} S(\mathrm{cal} / \mathrm{mol} \cdot \mathrm{K})$} \\
\hline & exp. $^{b}$ & calc. $^{c}$ & exp. ${ }^{b}$ & calc. $^{c}$ & exp. $^{b}$ & calc. $^{c}$ \\
\hline cinnamic acid & $334.5 \pm 2.0$ & 332.4 & $341.3 \pm 2.0$ & 340.3 & $23.0 \pm 2.0$ & 26.5 \\
\hline coumaric acid/-COOH & $332.7 \pm 2.0$ & 333.5 & $339.1 \pm 2.0$ & 341.8 & $21.5 \pm 2.0$ & 27.9 \\
\hline coumaric acid/-OH & $318.3 \pm 2.1$ & 319.9 & $324.2 \pm 2.1$ & 326.6 & $20.0 \pm 2.0$ & 22.7 \\
\hline caffeic acid/-COOH & $332.2 \pm 2.0$ & 332.8 & $339.1 \pm 2.0$ & 340.7 & $23.3 \pm 2.0$ & 26.6 \\
\hline caffeic acid/-OH & $317.3 \pm 2.2$ & $318.3^{d}$ & $323.3 \pm 2.2$ & $324.5^{d}$ & $20.4 \pm 2.0$ & $20.6^{d}$ \\
\hline & & $312.5^{e}$ & & $318.8^{e}$ & & $20.6^{e}$ \\
\hline
\end{tabular}

${ }^{a}$ Determined using the expression $\Delta_{\mathrm{a}} G=\Delta_{\mathrm{a}} H-T \Delta_{\mathrm{a}} S$, with $T=298.15 \mathrm{~K} .{ }^{b}$ This work. ${ }^{c}$ Calculated at the B3LYP/6-311++G(d,p) levels of theory, taking into account the contribution of populations of neutral and protonated conformers. ${ }^{d}$ Deprotonation at the $m$-OH position. ${ }^{e}$ Deprotonation at the $p$-OH position.

However, this interpretation of Figure 2 violates the equilibrium principle because a mixture of the reference acid with the bifunctional coumaric acid must generate a mixture of the two heterodimers, $\left[\mathrm{R}_{\mathrm{ref}} \mathrm{H} \cdot \mathrm{ABH}\right]^{-}$and $\left[\mathrm{HAB} \cdot \mathrm{H} \cdot \mathrm{R}_{\mathrm{ref}}\right]^{-}$, in a proportion determined by their thermodynamic stability, i.e., the $\Delta G$. Even if the barrier between the two forms is large, one would expect to produce both heterodimers, which, once formed, would not interconvert.

Nevertheless, it is interesting to proceed in the manner of Hoke et al. ${ }^{49}$ to determine the GA from the two lines. In Figure 2 , the $x$-intercept of the linear regression of the slopes can be used to obtain an approximate value of the GAs for both groups, which are 325.6 and $331.2 \mathrm{kcal} / \mathrm{mol}$ for the hydroxyl and carboxyl groups, respectively. A comparison of them with the computational results (Table 1) shows that the apparent GA of the hydroxyl group is less acidic than the expected value, while the carboxyl group is more acidic. The difference between the GAs of the two sites is only $5.6 \mathrm{kcal} / \mathrm{mol}$ compared to the expected $13.6 \mathrm{kcal} / \mathrm{mol}$. This large difference confirms that these data are not what they appear to be. Moreover, the much smaller GA difference between groups from the expected values indicates the presence of the two isomeric heterodimers in both trend lines.

Variation of the Heterodimer Population with the Experimental Conditions. The presence of a mixture of hydrogen bound clusters in the heterodimer population clearly undermines the GA measurement of each group separately. In order to obtain a reliable value, it will be necessary to eliminate or at least minimize the presence of mixed clusters in the heterodimer population. For that purpose, we investigated the effect on the heterodimer population of both temperature and solvent in the ESI source.

Effect of Drying Temperature on Heterodimer Population. The experiments in Figure 2 were carried out with the ESI drying gas at a temperature of $180{ }^{\circ} \mathrm{C}$ at which the heterodimer signal was maximized. However, as we explore the ratio of CID products for a particular heterodimer ( $p$-coumaric with benzoic acid) with temperature from 120 to $290{ }^{\circ} \mathrm{C}$, we noticed a marked variation in the product ratio, as shown in Figure 3. If we were dealing with a single heterodimer structure, there would be no dependence of this ratio on the temperature.

The variation observed with the temperature must be the result of a change in the heterodimer structure population. In particular, the results show that at high temperature, where the ratio of $\mathrm{A}^{-}$to $\mathrm{R}_{\mathrm{ref}}{ }^{-}$goes to 1 , we conclude that the benzoic acid is bonded exclusively to the carboxylic acid group because this structure can dissociate with nearly equal probability to either the benzoate anion or the coumaric anion at the acid end, the

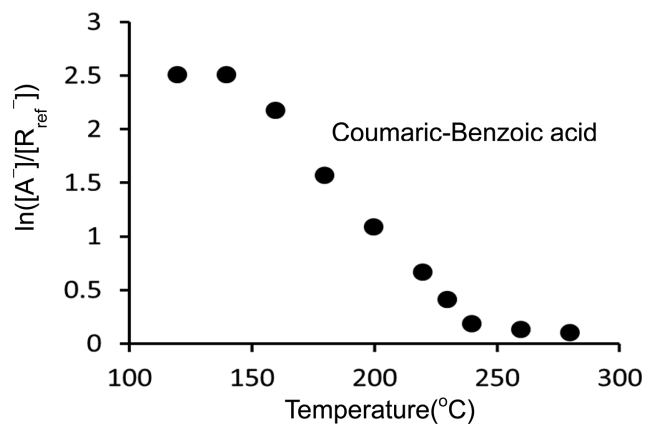

Figure 3. CID $\left(E_{\mathrm{cm}}=1.5 \mathrm{eV}\right)$ natural logarithm of the branching ratio variation with the drying gas temperature for the coumaric acidbenzoic acid heterodimer using a 1:1 mixture of water and acetonitrile as the solvent.

two groups that have nearly identical GAs. That is, we calculated the $\mathrm{COOH}$ end of coumaric acid to have $\mathrm{GA}=333.5$ $\mathrm{kcal} / \mathrm{mol}$ (Table 1 ), while a similar calculation for benzoic acid yielded $331.4 \mathrm{kcal} / \mathrm{mol}$. The latter value can be compared to the experimental value of $333.0 \mathrm{kcal} / \mathrm{mol}$ (Table S1, Supporting Information). However, why should the structure of the heterodimer depend upon the drying conditions in the source? What certainly changes with the drying temperature is the thermal energy content of the solvated heterodimer.

The importance of the solvation energy in the ESI efficiency has been pointed out by several groups. ${ }^{57-59}$ At low temperatures, the drying effect (solvent evaporation) is less efficient, but the desolvated heterodimers are more stable with respect to dissociation. As the temperature is increased, the increased thermal energy of the heterodimer increases the drying efficiency but also results in the dissociation of the heterodimer. There is thus an optimum temperature where the two effects, drying efficiency and vapor phase dimer dissociation, are balanced to generate a high yield of desolvated heterodimers.

In order to shed light on the results of Figure 3, we calculated the enthalpies of formation (Table 2) of all the species involved in the electrospray process of heterodimer formation, evaporation, and dissociation for the case of coumaric and benzoic acids (BA). In Figure 4, the calculated enthalpies of the two coumaric-benzoic acid heterodimers, in water, acetonitrile, as well as in the gas phase, are shown. Corresponding calculations for the caffeic and benzoic acid system yielded binding and solvation energies that were within $2 \mathrm{kcal} / \mathrm{mol}$ of those in Figure 4. Thus, we can take Figure 4 as representative of all the systems investigated here. 
Table 2. Gas-Phase Heats of Formation and Solvation Enthalpies of Benzoic and Coumaric Acids and Their Heterodimers

\begin{tabular}{|c|c|c|c|}
\hline compound & $\Delta_{\mathrm{f}} H_{m}^{0}(\mathrm{~g})(\mathrm{kcal} / \mathrm{mol})$ & $\Delta_{\text {solv }} H\left(\mathrm{H}_{2} \mathrm{O}\right)^{a}(\mathrm{kcal} / \mathrm{mol})$ & $\Delta_{\text {solv }} H(\mathrm{ACN})^{a}(\mathrm{kcal} / \mathrm{mol})$ \\
\hline benzoic acid (BA) & $-70.3 \pm 0.5^{b}$ & 5.1 & 5.0 \\
\hline deprotonaed benzoic acid $\left(\mathrm{BA}^{-}\right)$ & $-97.2 \pm 2.4^{c}$ & 60.3 & 59.2 \\
\hline coumaric acid & $-97.5 \pm 1.1^{d}$ & 9.1 & 8.9 \\
\hline$[\mathrm{Coum} / \mathrm{COO}]^{-}$ & $-125.3 \pm 2.3^{c, e}$ & 65.2 & 64.0 \\
\hline$[\mathrm{Coum} / \mathrm{O}]^{-}$ & $-140.5 \pm 2.3^{c_{f} f}$ & 49.6 & 48.7 \\
\hline heterodimer $[\text { Coum } / \mathrm{COO}-\mathrm{H}-\mathrm{BA}]^{-}$ & $-218.4^{g}$ & 58.5 & 57.2 \\
\hline heterodimer $[\text { Coum } / \mathrm{O}-\mathrm{H}-\mathrm{BA}]^{-}$ & $-229.5^{h}$ & 47.1 & 46.2 \\
\hline
\end{tabular}

${ }^{a}$ Obtained at the B3LYP/6-311++G(d,p) level. ${ }^{b}$ Taken from Pedley. ${ }^{60}{ }^{c}$ Obtained from the equation $\mathrm{AH} \rightarrow \mathrm{A}^{-}+\mathrm{H}^{+}$, with $\Delta_{\mathrm{a}} H=340.1 \pm 2.0 \mathrm{kcal} /$ mol (NIST). ${ }^{d}$ Obtained from Dávalos et al. ${ }^{61}{ }^{e}$ With $\Delta_{\mathrm{a}} H=339.1 \pm 2.0 \mathrm{kcal} / \mathrm{mol}$ (our work). ${ }^{f}$ With $\Delta_{\mathrm{a}} H=324.2 \pm 2.1 \mathrm{kcal} / \mathrm{mol}$ (our work). ${ }^{g}$ Average value estimated using isodesmic reactions: [Coum/COO-H-BA $]^{-} \rightarrow$ Coumaric $+\mathrm{BA}^{-}$(or [Coum/COO $\left.]^{-}+\mathrm{BA}\right) .{ }^{h}$ Average value estimated using isodesmic reactions: $[\text { Coum } / \mathrm{O}-\mathrm{H}-\mathrm{BA}]^{-} \rightarrow$ Coumaric $+\mathrm{BA}^{-}\left(\right.$or $\left.[\text {Coum } / \mathrm{O}]^{-}+\mathrm{BA}^{-}\right)$.

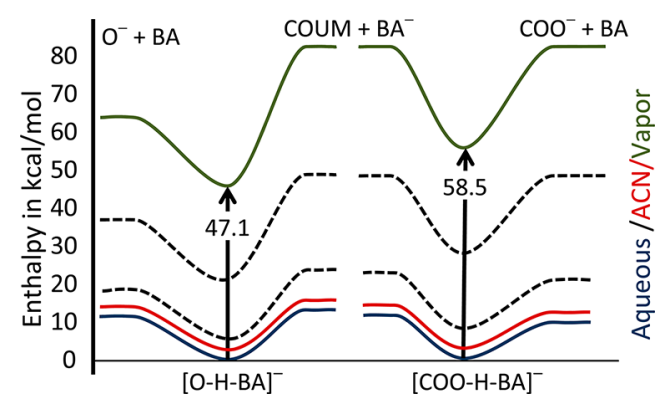

Figure 4. Calculated $[\mathrm{B} 3 \mathrm{LYP} / 6-311++\mathrm{G}(\mathrm{d}, \mathrm{p})]$ energetic profile of the coumaric-benzoic acid heterodimers in water, acetonitrile, and in the gas phase at $298.15 \mathrm{~K}$. [O-H-BA $]^{-}$corresponds to the anionic cluster bound to the hydroxyl group of the $p$-coumaric acid, while $[\mathrm{COO}-\mathrm{H}-\mathrm{BA}]^{-}$corresponds to the heterodimer formed through the carboxylic group. The dissociation products are as follows: COUM, coumaric acid; $\mathrm{O}^{-}$, coumaric acid hydroxide anion; $\mathrm{COO}^{-}$, coumaric acid carboxylate anion; $\mathrm{BA}$, benzoic acid; $\mathrm{BA}^{-}$, benzoic acid anion. The dashed curves are suggested enthalpies of partially solvated clusters.

These results show a large difference in the solvation enthalpies of the two heterodimers: $47.1 \mathrm{kcal} / \mathrm{mol}$ when the benzoic acid is attached to the $\mathrm{OH}$ group, $[\mathrm{O}-\mathrm{H}-\mathrm{BA}]^{-}$, and $57.5 \mathrm{kcal} / \mathrm{mol}$ when it is attached at the acid group, [COO$\mathrm{H}-\mathrm{BA}]^{-}$. This is true for both water and acetonitrile as solvents. Schröder et al. ${ }^{48}$ recently reported a similar pattern for the free energies of the $p$-hydroxybenzoic acid anions in water and acetonitrile, although, in that case, the carboxylate anion was about $2.5 \mathrm{kcal} / \mathrm{mol}$ more stable than the phenoxide ion. Although acetonitrile is aprotic, it does have a large dipole moment of $3.92 \mathrm{D}$, compared to 1.85 for water and thus is a good solvent for polar molecules. ${ }^{62}$ Thus, for either solvent, the $\mathrm{OH}-$ benzoic acid heterodimer needs about $10 \mathrm{kcal} / \mathrm{mol}$ less energy to be desolvated than the $\mathrm{COOH}$-benzoic cluster. Hence, at low drying gas temperatures, only the $\mathrm{OH}$-benzoic acid clusters will be converted effectively to the gas phase, while the $[\mathrm{COO}-\mathrm{H}-\mathrm{BA}]^{-}$heterodimer will remain at least partially solvated. Apparently, according to Figure 3, at temperatures below $150{ }^{\circ} \mathrm{C}$, only the $[\mathrm{O}-\mathrm{H}-\mathrm{BA}]^{-}$heterodimer anion is fully desolvated. However, as the drying gas temperature increases, more of the solvated $\mathrm{COOH}-$ benzoic acid population has enough energy to move to the gas phase, and as a consequence, the ratio of the products after the CID (Figure 3) starts to decrease.

At still higher temperatures, the total intensity of the heterodimer signal begins to decrease. We propose that this is due to the increased internal energy which causes the gas-phase heterodimers to dissociate. It is evident from Figure 4 that the binding energy for the $[\mathrm{O}-\mathrm{H}-\mathrm{BA}]^{-}$heterodimer is about 15 $\mathrm{kcal} / \mathrm{mol}$ less (via the $\mathrm{O}^{-}+\mathrm{BA}$ dissociation channel) so that this heterodimer is preferentially lost more than the [COO$\mathrm{H}-\mathrm{BA}]^{-}$heterodimer. When we reach $250{ }^{\circ} \mathrm{C}$, the ratio of the CID products stabilizes, which we propose is the temperature above which all of the $[\mathrm{O}-\mathrm{H}-\mathrm{BA}]^{-}$has dissociated in the gas phase, and the only gas-phase heterodimer remaining is the more stable $[\mathrm{COO}-\mathrm{H}-\mathrm{BA}]^{-}$heterodimer. As pointed out before, the equal $\mathrm{BA}^{-}$and $\mathrm{COO}^{-}$signals $\left(\ln \left[\mathrm{COO}^{-}\right] /\left[\mathrm{BA}^{-}\right]=\right.$ 0 ) imply that the GAs of the two dissociation channels are equal, as is evident by the similar enthalpies in Figure 4. It is interesting that these two features are a property primarily of the carboxylic acid and $\mathrm{OH}$ groups of the coumaric and caffeic acids, because similar energy diagrams are obtained with other reference acids.

In support of the above interpretation, we show in Figure 5 the percent heterodimer population remaining after CID as a

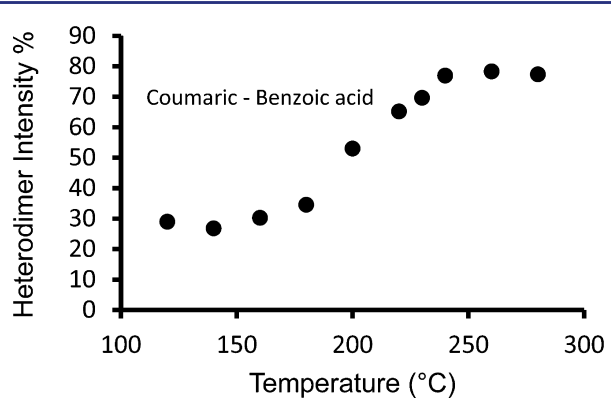

Figure 5. Heterodimer abundance variation (in normalized intensity) after $\operatorname{CID}\left(E_{\mathrm{cm}}=1.5 \mathrm{eV}\right)$ against the drying gas temperature for the coumaric acid-benzoic acid heterodimer.

function of the drying gas temperature. The increase suggests that, at high drying gas temperature, the heterodimer ion is more stable, and less subject to dissociation. This is perfectly explained by the energy diagram in Figure 4.

At low drying temperatures, where only the $[\mathrm{O}-\mathrm{H}-\mathrm{BA}]^{-}$is desolvated, $70 \%$ of the heterodimers are dissociated by the CID process and $30 \%$ remain stable as dimers. However, as the temperature is increased, we obtain a mixture of heterodimers, which now includes the more stable $[\mathrm{COO}-\mathrm{H}-\mathrm{BA}]^{-}$ heterodimer, which results in the increased fraction of stable heterodimers. By the time we reach $240{ }^{\circ} \mathrm{C}$, only the [COO$\mathrm{H}-\mathrm{BA}]^{-}$heterodimer remains (the $\mathrm{OH}$ bound dimer having been removed prior to CID by the thermal decomposition), and the fraction of heterodimers remaining after CID levels off at $80 \%$. 
The temperature effect was tested for every reference acid in this study. For both coumaric and caffeic acid heterodimers, the increase in the temperature shifts the abundance ratio to lower values and therefore to the carboxyl bound subpopulation. Although the quantitative details in Figure 4 vary somewhat from one reference acid to another, the two major qualitative features (the higher solvation energy for the acid bound heterodimer and the lower gas-phase dissociation energy of the $\mathrm{OH}$ bound heterodimer) remain the same. No variation was observed when the sample was cinnamic acid with only one deprotonation site.

Effect of Solvent on Heterodimer Population. Because the solvation energy is proposed to play such an important role in these experiments (as also reported by others in recent publications ${ }^{44-46,48}$ ), varying of the solvent should result in predictable changes, as is indeed observed. Figure 6 shows the

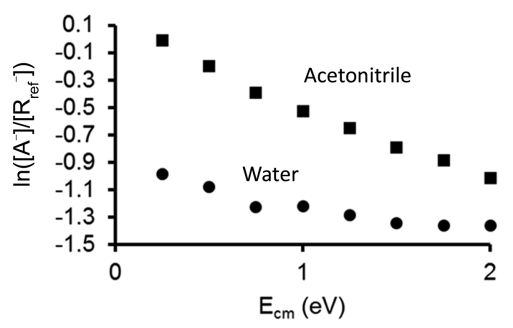

Figure 6. Natural logarithm of the branching ratio at different CID energies for $p$-coumaric acid with $p$-nitrophenol as a reference at 180 ${ }^{\circ} \mathrm{C}$, using water (circles) or acetonitrile (squares) as a solvent.

evolution of the branching ratios with the energy $\left(E_{\mathrm{cm}}\right)$ for the heterodimers between coumaric acid and p-nitrophenol in either water or acetonitrile. Measurements with other aprotic and nonpolar solvents yielded results that were very similar to those with acetonitrile. In addition and as expected, no variations in the branching ratios with the solvent were observed in the monofunctional cinnamic acid experiments. These experiments were carried out at a temperature of $180^{\circ} \mathrm{C}$, where the signal was optimized.

The data in Figure 6 show two effects. First, the coumaric acid signal $\left(\mathrm{COUM}^{-}=\right.$sum of $\mathrm{O}^{-}$and $\left.\mathrm{COO}^{-}\right)$is less with water as the solvent than with acetonitrile. Second, the COUM $^{-}$signal decreases with increasing CID kinetic energy. All previous data presented so far in Figures 2, 3, and 5 were collected at $E_{\mathrm{cm}}=1.5 \mathrm{eV}$. At this energy, the relative $\left[\mathrm{COUM}^{-} /\right.$ $\mathrm{A}_{\mathrm{ref}}{ }^{-}$] signal is nearly 5 times greater in acetonitrile than in water. To explain this, we can use the energy diagram in Figure 4, which is qualitatively similar for benzoic acid and $p$ nitrophenol as reference acids. As already pointed out, the calculated solvation energies in water and acetonitrile are nearly identical so that the different observed properties exhibited in Figure 6 are not a result of the solvation energies. As already mentioned, the same conclusion was reported by Schroeder et $\mathrm{al}^{48}$ on the basis of a $\mathrm{pH}$ dependent NMR study of $p$ hydroxybenzoic acid in deuterated water as well as acetonitrile. This finding was in accord with their DFT solvation calculation, which showed that the solvation energies of these acids are similar in water and acetonitrile. However, no one has offered an explanation. Why is the vapor phase $[\mathrm{O}-\mathrm{H}-\mathrm{BA}]^{-}$ heterodimer preferred when using the acetonitrile solvent? The main difference between these two solvents is their vapor pressure. Acetonitrile boils at about $80{ }^{\circ} \mathrm{C}$, so that its vapor pressure is considerably less than that of water. Thus, at a given temperature, the acetonitrile solvent should vaporize more readily than the water solvated dimers. That is, switching from water to $\mathrm{ACN}$ should be equivalent to lowering the drying temperature, which we have already shown to favor the desolvated $[\mathrm{O}-\mathrm{H}-\mathrm{BA}]^{-}$structure.

The second feature in Figure 6 is the decreasing $\left[\mathrm{COUM}^{-} /\right.$ $\mathrm{R}_{\mathrm{ref}}{ }^{-}$] ratio with increasing $E_{\mathrm{cm}}$. This is explained most simply by the Le Chatelier principle, which states that, as the system energy is increased, the endothermic channel (COUM $+\mathrm{R}_{\text {ref }}{ }^{-}$) will be preferred. In the limit of very high energy, the enthalpy differences will become unimportant, and only the entropy will determine the final branching ratios.

Extended Kinetic Method Analysis. trans-Cinnamic Acid. Four compounds with GAs ranging from 337.1 to $332.3 \mathrm{kcal} / \mathrm{mol}$ (see Table $\mathrm{S} 1$ in the Supporting Information) were chosen as references: benzoic acid, phenylacetic acid, 3toluic acid, and 2-chlorophenol. The CID branching ratios of the product ions were recorded at eight collision energies $\left(E_{\mathrm{cm}}\right)$, from 0.25 to $2 \mathrm{eV}$. As a result of the lability of the carboxyl linkage, secondary fragmentation becomes apparent in the spectra at collision energies in excess of $2 \mathrm{eV}$. The natural logarithms of the branching ratios, $\ln \left(\left[\mathrm{A}^{-}\right] /\left[\mathrm{R}_{\mathrm{ref}}{ }^{-}\right]\right)$, were plotted against the values of $\Delta_{\mathrm{a}} H_{\text {ref }}-\Delta_{\mathrm{a}} H_{\text {avg }}$ (Figure 7).

Linear regression with a least-squares fit of the data points at each collision energy yields a straight line with the slope $1 / R T_{\text {eff }}$ and the $y$-intercept of $-\left[\left(\Delta_{\mathrm{a}} H-\Delta_{\mathrm{a}} H_{\text {avg }}\right) / R T_{\text {eff }}-\Delta(\Delta S) / R\right]$. For each data point, the uncertainty in the $x$-axis was the average error of $\Delta_{\mathrm{a}} H_{\text {ref }}$ for the corresponding reference acids (Table S1 in the Supporting Information), while the error for the $y$-axis values was taken as 0.05 .

The $\Delta_{\mathrm{a}} H$ of the cinnamic acid was obtained from the second set of thermo-kinetic plots. The values of the $y$-intercepts obtained in the first plot were plotted against its corresponding slopes (Figure 7.). The linear regression with a least-squares fit of the data points gives a straight line with a slope of $\Delta_{\mathrm{a}} \mathrm{H}-$ $\Delta_{\mathrm{a}} H_{\mathrm{avg}}$ and an intercept of $-\Delta(\Delta S) / R$ (Tables S2 and S3, Supporting Information).

As suggested by Armentrout, ${ }^{29}$ the uncertainties of the first thermo-kinetic plot were included in the second one. Our experimentally measured $\Delta_{\mathrm{a}} H, \Delta_{\mathrm{a}} S$, and $\Delta_{\mathrm{a}} G$ (GA) for cinnamic acid were thus obtained from the $\Delta_{\mathrm{a}} H_{\text {avg, }}, \Delta_{\mathrm{a}} S_{\text {avg }}$, and their uncertainties, and are shown as the experimental values in Table 1 . The resulting slopes $(m)$, intercepts $(b)$, effective temperatures $\left(T_{\text {eff }}\right)$, as well as the resulting uncertainties are summarized in Tables S2 and S3 (Supporting Information).

Isomer Selected Coumaric and Caffeic Acids. We have established that we can prepare the heterodimer of the bifunctional $p$-coumaric and caffeic acids exclusively bound to the carboxylic acid, and that we can vary the conditions to strongly favor the $\mathrm{OH}$ bound dimer. We can thus use these conditions to determine the GA for both sites. Four compounds with GAs ranging from 334.3 to $332.9 \mathrm{kcal} / \mathrm{mol}$ were chosen as references for measuring the carboxyl groups of both hydroxycinnamic acids: phenylacetic acid, 3-toluic acid, benzoic acid, and 4-tert-butyl benzoic acid (GAs listed in Table S1, Supporting Information). As described previously, the experiments were performed using water as the ESI solvent and adjusting the temperature of the drying gas to high values $\left(\approx 250{ }^{\circ} \mathrm{C}\right)$. The results were analyzed in the same manner as for cinnamic acid and are shown in Figure 7. The final derived thermochemical results are summarized in Table 1. 

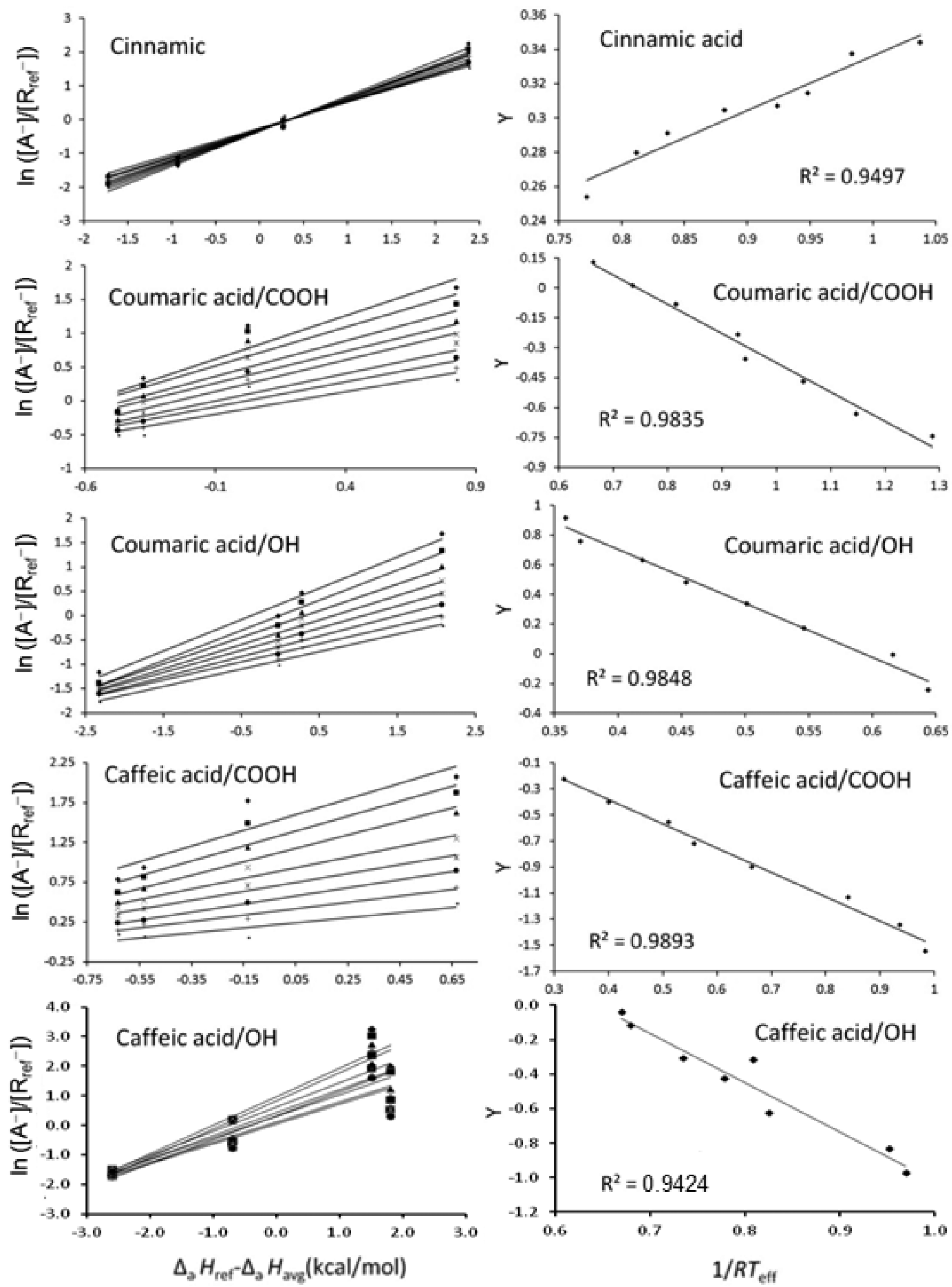

Figure 7. First and second sets of thermokinetic plots for the monofunctional cinnamic acid, the $\mathrm{OH}$ and $\mathrm{COOH}$ groups of coumaric acid, and the $\mathrm{OH}$ and $\mathrm{COOH}$ groups of caffeic acid, using data from selected organic acids.

The acidites of the hydroxyl groups were measured using four reference acids with GAs ranging from 322.6 to $317.8 \mathrm{kcal} /$ mol (4-nitro-5-methylphenol, 4-nitrobenzoic acid, 4-nitrophenol, and 2-hydroxy-benzoic acid-see Table S1, Supporting 
Information) for coumaric acid and four reference acids with GAs ranging from 320.9 to $316.6 \mathrm{kcal} / \mathrm{mol}$ (4-nitrophenol, penta-fluorophenol, 2-hydroxy-benzoic acid, and penta-fluorobenzoic acid-see Table S1, Supporting Information) for caffeic acid. The experiments were performed using pure acetonitrile as solvent and adjusting the temperature of the drying gas to low values $\left(\approx 25{ }^{\circ} \mathrm{C}\right)$ in order to maximize binding at the hydroxyl groups. The results are plotted in Figure 7 .

The derived experimental thermochemical values are listed in Table 1. The comparison between the experimental and calculated thermochemical properties demonstrates excellent agreement in the case of coumaric acid at the $\mathrm{COOH}$ and $\mathrm{OH}$ sites as well as for caffeic acid at the $\mathrm{COOH}$ site. In the case of the caffeic acid, there are two adjacent $\mathrm{OH}$ sites which have different calculated acidities. On the basis of the agreement between the measured and calculated acidities, it appears that the reference acids are binding the $\mathrm{OH}$ group at the meta position. On the other hand, the difference in the GAs of these two sites is not so great to permit us to state this with much confidence; hence, we assumed an average group behavior for the hydroxyl moiety of the caffeic acid.

\section{DISCUSSION}

This detailed investigation of multifunctional heterodimers has led us to the development of general experimental approaches for selecting individual gas-phase heterodimers. These results have shown that, by lowering the drying temperature in the ESI source, we can direct the process to generate exclusively the $\mathrm{OH}$ bound heterodimer, which has the lowest solvation energy. In a related approach, by replacing the water solvent with the lower boiling acetonitrile, we again favor the production of the solvated $\mathrm{OH}$ bound heterodimer because the solvent is more easily removed at a given temperature. We can preferentially favor the gas-phase $\mathrm{COOH}$ bound heterodimer by increasing the drying temperature because the gas-phase $\mathrm{OH}$ bound dimer dissociates due to its internal energy and low dissociation energy toward the $\mathrm{O}^{-}+\mathrm{R}_{\text {ref }}$ products. That is, we use the higher temperature to destroy the less stable gas-phase heterodimers. Finally, we conclude on the basis of solvation calculations that, because the solvation properties of acetonitrile are not so different from those of water, the concentrations of the heterodimers in solution are largely independent of the solvent and that our ability to control which gas-phase heterodimer is produced is solely a function of the desolvation process.

The only equilibration between the heterodimers probably takes place in the solvated (or partially solvated) states by dissociative collisions and redimerization. This is because the two functional groups are separated by at least $10 \AA$ so that the barrier for unimolecular isomerization in solution or the vapor phase is most likely higher than the simple dissociation in solution, which costs only about $12 \mathrm{kcal} / \mathrm{mol}$. Once the heterodimers are airborne, the structures are locked into their conformations and the barriers, as shown in Figure 4, increase substantially.

How general are these conclusions? Certainly the change in the acidity of solvated and gas-phase ions has been well established so that most acids with bifunctional groups will have different solvation energies. Thus, using the drying temperature as a means of favoring the gas-phase isomer with the higher acidity (lower energy) should work with most molecules having different bifunctional acidic groups.
The analysis with the extended kinetic method has yielded GAs that compare very favorably with calculated acidities. In the case of the cinnamic acid, the experimental results in Table 1 show a good agreement with the computational ones. Although the measurement of the GA of monofunctional cinnamic acid by the EKM did not offer a new scientific challenge, its determination was necessary in order to compare the results with those of the bifunctional hydroxycinnamic acids. Nevertheless, it is the first time that the GA of this compound has been experimentally determined.

The GAs of the carboxyl and hydroxyl groups of the coumaric and caffeic acid have been also determined. The results are in good agreement with the calculated ones (see Table 1) and confirm that, when selection of specific proton bound clusters is possible, the EKM can be used to determine the thermochemical parameters of local groups within the molecule.

In the case of $\mathrm{OH}$ groups in caffeic acid, the comparison between our measured and calculated GAs suggests that the binding of the reference acids occurs exclusively at the meta position. Because these two $\mathrm{OH}$ groups are adjacent to each other, we would expect that the reference acid could bind to either one and that equilibration between the two sites should be possible even in the gas phase. In fact, our calculations of the heterodimer structures (see Figure S2b in the Supporting Information) show that benzoic acid binds to the $\mathrm{OH}$ and $\mathrm{O}^{-}$ groups in a symmetric fashion in both the solvated and gasphase media, with the two $\mathrm{H}$ atoms considerably closer to the caffeic acid than the benzoic acid. Thus, if the collisional dissociation product were to produce the neutral benzoic acid, it could break either of the $\mathrm{O}-\mathrm{H}$ bonds.

\section{CONCLUSIONS}

We have used the extended kinetic method along with computational studies to determine the GA, $\Delta_{\mathrm{a}} H$, and $\Delta_{\mathrm{a}} \mathrm{S}$ for the cinnamic acid, as well as the carboxyl and hydroxyl groups of coumaric and caffeic acid. In order to determine these thermochemical values for the bifunctional coumaric and caffeic acids, it was necessary to develop an experimental method for selective generation of single isomeric species in the ESI source. This was accomplished by taking advantage of the different solvation energies of the various heterodimers as well as differences in the gas-phase stability of the heterodimers. Varying the drying gas temperature and the solvent (water and acetonitrile) permitted us to generate binding of reference acids to either the $\mathrm{COOH}$ or $\mathrm{OH}$ groups in coumaric and caffeic acids. These results confirm that the kinetic method can be applied to determine thermochemical parameters of local groups when the selective formation or selection of specific hydrogen bounded clusters is possible. We furthermore conclude that our ability to select the gas-phase heterodimer is based soley on control of the desolvation process and not on the initial concentration of the heterodimers in the solution phase.

\section{ASSOCIATED CONTENT}

\section{S Supporting Information}

Theoretical molecular geometries, gas-phase thermochemical quantities of the reference acids, as well as the results of thermo-kinetic plots. This material is available free of charge via the Internet at http://pubs.acs.org. 


\section{AUTHOR INFORMATION}

\section{Corresponding Author}

andguerrero@ucdavis.edu; jdavalos@iqfr.csic.es

\section{Present Addresses}

${ }^{\dagger}$ A.G.: Department of Chemistry, University of California at Davis, Davis, CA 95616.

${ }^{\ddagger}$ T.B.: Department of Chemistry, University of North Carolina, Chapel Hill, NC 27599-3290.

\section{Notes}

The authors declare no competing financial interest.

\section{ACKNOWLEDGMENTS}

This study was supported by a grant (Project. No. CTQ200913652) from the Spanish MEC/MICINN. A.G. thanks Prof. M. $\mathrm{T}$. Rodgers for very helpful discussions during the Gordon Research Conference on Gaseous Ions: Structures, Energetics \& Reactions, Galveston, 2011. We also thank the very helpful comments of three reviewers of this paper. T.B. is grateful for financial support from the Spanish MICINN (Ref. SAB20090028) for a four month visit to Madrid.

\section{REFERENCES}

(1) McMahon, T. B.; Kebarle, P. J. Am. Chem. Soc. 1985, 107, 26122617

(2) Kemper, P. R.; Hsu, M. T.; Bowers, M. T. J. Phys. Chem. 1991, 95, 10600-10609.

(3) Wolf, J. F.; Staley, R. H.; Koppel, I.; Taagepera, M.; McIver, R. T.; Beauchamp, J. L.; Taft, R. W. J. Am. Chem. Soc. 1977, 99, 5417-5429.

(4) Bartmess, J. E.; Scott, J. A.; McIver, R. T. J. Am. Chem. Soc. 1979, $101,6046-6056$.

(5) Bowers, M. T., Ed. Gas phase ion chemistry; Academic Press: New York, 1979; Vol. 2.

(6) Larson, J. W.; McMahon, T. B. J. Am. Chem. Soc. 1985, 107, 766773.

(7) Freiser, B. S., Ed. Organometallic ion chemistry; Kluwer Academic Publishers: Dordrecht, The Netherlands; Boston, MA, 1996.

(8) Brauman, J. I.; Chabinyc, M. L. J. Phys. Chem. A 1999, 103, 9163-9166.

(9) Jarek, R. L.; Miles, T. D.; Trester, M. L.; Denson, S. C.; Shin, S. K. J. Phys. Chem. A 2000, 104, 2230-2237.

(10) Hurtado, M.; Yáñez, M.; Herrero, R.; Guerrero, A.; Dávalos, J. Z.; Abboud, J.-L. M.; Khater, B.; Guillemin, J.-C. Chem.-Eur. J. 2009, $15,4622-4629$.

(11) Bohme, D. K.; Mackay, G. I.; Schiff, H. I. J. Chem. Phys. 1980, 73, 4976-4986.

(12) Adams, N. G.; Babcock, L. M. Advances in gas phase ion chemistry; JAI Press: Greenwich, CT, 1992; Vol. 3.

(13) Seburg, R. A.; Hill, B. T.; Squires, R. R. J. Chem. Soc., Perkin Trans. 2 1999, 2249-2256.

(14) Decker, B. K.; Adams, N. G.; Babcock, L. M. Int. J. Mass Spectrom. 1999, 187, 727-743.

(15) Ohair, R. A. J.; Depuy, C. H.; Bierbaum, V. M. J. Phys. Chem. 1993, 97, 7955-7961.

(16) Simoes, J. A. M. Energetics of organometallic species; Kluwer Academic: Dordrecht, The Netherlands; Boston, MA, 1992.

(17) Natterer, J.; Koch, W.; Schroder, D.; Goldberg, N.; Schwarz, H. Chem. Phys. Lett. 1994, 229, 429-434.

(18) Esseffar, M.; Herrero, R.; Quintanilla, E.; Davalos, J. Z.; Jimenez, P.; Abboud, J. L. M.; Yáñez, M.; Mo, O. Chem.—Eur. J. 2007, 13, 1796-1803.

(19) Bouchoux, G.; Salpin, J. Y.; Leblanc, D. Int. J. Mass Spectrom. Ion Processes 1996, 153, 37-48.

(20) Bouchoux, G.; Salpin, J. Y. Rapid Commun. Mass Spectrom. 1999, 13, 932-936.

(21) Bouchoux, G.; Salpin, J. Y. J. Phys. Chem. 1996, 100, 1655516560 .
(22) Cooks, R. G.; Kruger, T. L. J. Am. Chem. Soc. 1977, 99, 12791281.

(23) McLuckey, S. A.; Cameron, D.; Cooks, R. G. J. Am. Chem. Soc. 1981, 103, 1313-1317.

(24) Cheng, X. H.; Wu, Z. C.; Fenselau, C. J. Am. Chem. Soc. 1993, $115,4844-4848$.

(25) Fabris, D.; Kelly, M.; Wu, Z.; Fenselau, C. Rapid Commun. Mass Spectrom. 1994, 8, 791-795.

(26) Cerda, B. A.; Wesdemiotis, C. J. Am. Chem. Soc. 1996, 118, 11884-11892.

(27) Wesdemiotis, C.; Cerda, B. A.; Hoyau, S.; Ohanessian, G. J. Am. Chem. Soc. 1998, 120, 2437-2448.

(28) Nold, M. J.; Cerda, B. A.; Wesdemiotis, C. J. Am. Soc. Mass Spectrom. 1999, 10, 1-8.

(29) Armentrout, P. B. J. Am. Soc. Mass Spectrom. 2000, 11, 371-379.

(30) Bourgoin-Voillard, S.; Afonso, C.; Lesage, D.; Zins, E.-L.; Tabet, J.-C.; Armentrout, P. B. J. Am. Soc. Mass Spectrom. 2013, 24, 365-380.

(31) Ervin, K. M.; Armentrout, P. B. J. Mass Spectrom. 2004, 39, 1004-1015.

(32) Ervin, K. M. J. Mass Spectrom. 2002, 13, 435-452.

(33) Cooks, R. G.; Koskinen, J. T.; Thomas, P. D. J. Mass Spectrom. 1999, 34, 85-92.

(34) Ricci, A.; Piccolella, S.; Pepi, F.; Patsilinakos, A.; Ragno, R.; Garzoli, S.; Giacomello, P. J. Mass Spectrom. 2012, 47, 1488-1494.

(35) Riffet, V.; Bourcier, S.; Bouchoux, G. Int. J. Mass Spectrom. 2012, 316-318, 47-56.

(36) Bouchoux, G.; Bourcier, S.; Blanc, V.; Desaphy, S. J. Phys. Chem. B 2009, 113, 5549-5562.

(37) Tao, W. A.; Zhang, D.; Nikolaev, E. N.; Cooks, R. G. J. Am. Chem. Soc. 2000, 122, 10598-10609.

(38) Kumari, S.; Prabhakar, S.; Sivaleela, T.; Lakshmi, V. V.; Vairamani, M. Eur. J. Mass Spectrom. 2009, 15, 35-43.

(39) Bouchoux, G. Mass Spectrom. Rev. 2007, 26, 775-835.

(40) Kurinovich, M. A.; Lee, J. K. J. Am. Chem. Soc. 2000, 122, 62586262.

(41) Tian, Z.; Kass, S. R. J. Am. Chem. Soc. 2008, 130, 10842-10843.

(42) Brauman, J. I.; Blair, L. K. J. Am. Chem. Soc. 1970, 92, 59865992.

(43) Joyce, J. R.; Richards, D. J. Am. Soc. Mass Spectrom. 2011, 22, $360-368$.

(44) Steill, J. D.; Oomens, J. J. Am. Chem. Soc. 2009, 131, 1357013571.

(45) Tian, Z.; Kass, S. R. Angew. Chem., Int. Ed. 2009, 48, 13211323.

(46) Tian, Z.; Wang, X.-B.; Wang, L.-S.; Kass, S. R. J. Am. Chem. Soc. 2008, 131, 1174-1181.

(47) Schmidt, J.; Meyer, M. M.; Spector, I.; Kass, S. R. J. Phys. Chem. A 2011, 115, 7625-7632.

(48) Schröder, D.; Buděšínský, M.; Roithová, J. J. Am. Chem. Soc. 2012, 134, 15897-15905.

(49) Hoke, S. H.; Yang, S. S.; Cooks, R. G.; Hrovat, D. A.; Borden, W. T. J. Am. Chem. Soc. 1994, 116, 4888-4892.

(50) Bouchoux, G.; Djazi, F.; Gaillard, F.; Vierezet, D. Int. J. Mass Spectrom. 2003, 227, 479-496.

(51) Fournier, F.; Afonso, C.; Fagin, A.; Gronert, S.; Tabet, J.-C. J. Am. Soc. Mass Spectrom. 2008, 19, 1887-1896.

(52) NIST Chemistry Webbook. Standard Reference Database Number 69; Release June 2005; Linstrom, P. J., Mallard, W. G., Eds.; National Institute of Standards and Technology: Gaithersburg, MD, 2012 (http://webbook.nst.gov).

(53) Frisch, M. J.; Trucks, G. W.; Schlegel, H. B.; Scuseria, G. E.; Robb, M. A.; Cheeseman, J. R.; Scalmani, G.; Barone, V.; Mennucci, B.; Petersson, G. A.; Nakatsuji, H.; Caricato, M.; Li, X.; Hratchian, H. P.; Izmaylov, A. F.; Bloino, J.; Zheng, G.; Sonnenberg, J. L.; Hada, M.; Ehara, M.; Toyota, K.; Fukuda, R.; Hasegawa, J.; Ishida, M.; Nakajima, T.; Honda, Y.; Kitao, O.; Nakai, H.; Vreven, T.; Montgomery, J. A., Jr.; Peralta, J. E.; Ogliaro, F.; Bearpark, M.; Heyd, J. J.; Brothers, E.; Kudin, K. N.; Staroverov, V. N.; Kobayashi, R.; Normand, J.; Raghavachari, K.; Rendell, A.; Burant, J. C.; Iyengar, S. S.; Tomasi, J.; Cossi, M.; Rega, 
N.; Millam, J. M.; Klene, M.; Knox, J. E.; Cross, J. B.; Bakken, V.; Adamo, C.; Jaramillo, J.; Gomperts, R.; Stratmann, R. E.; Yazyev, O.; Austin, A. J.; Cammi, R.; Pomelli, C.; Ochterski, J. W.; Martin, R. L.; Morokuma, K.; Zakrzewski, V. G.; Voth, G. A.; Salvador, P.; Dannenberg, J. J.; Dapprich, S.; Daniels, A. D.; Farkas, Ö.; Foresman, J. B.; Ortiz, J. V.; Cioslowski, J.; Fox, D. J. Gaussian 09, revision A.02; Gaussian, Inc.: Wallingford, CT, 2009.

(54) Becke, A. D. J. Chem. Phys. 1993, 98, 5648-5652.

(55) Lee, C.; Yang, W.; Parr, R. G. Phys. Rev. B 1988, 37, 785-789.

(56) Tomasi, J.; Mennucci, B.; Cammi, R. Chem. Rev. 2005, 105, 2999-3094.

(57) Wang, G.; Cole, R. B. Anal. Chem. 1998, 70, 873-881.

(58) Null, A. P.; Nepomuceno, A. I.; Muddiman, D. C. Anal. Chem. 2003, 75, 1331-1339.

(59) Leize, E.; Jaffrezic, A.; Van Dorsselaer, A. J. Mass Spectrom. 1996, $31,537-544$.

(60) Pedley, J. B. Thermochemical Data and Structures of Organic Compounds; Thermodynamics Research Center: College Station, TX, 1994

(61) Dávalos, J. Z.; Herrero, R.; Chana, A.; Guerrero, A.; Jiménez, P.; Santiuste, J. M. J. Phys. Chem. A 2012, 116, 2261-2267.

(62) Nelson, R. D., Jr.; Lide, D. R., Jr.; Maryott, A. A. Selected Values of Electric Dipole Moments for Molecules in the Gas Phase; US Government Printing Office: Washington DC, 1967; Vol. NSRDSNBS10. 